\title{
Pressure-induced dissociation of casein micelles: size distribution and effect of temperature
}

\section{R. Gebhardt ${ }^{1}$, \\ W. Doster ${ }^{1}$ and \\ U. Kulozik ${ }^{2}$}

${ }^{1}$ Physics Department E13, Technical University Munich, Garching, Germany

${ }^{2}$ Department for Food and Nutrition, Freising-Weihenstephan, Germany

\section{Correspondence \\ W. Doster \\ Physikdepartment E13 \\ Technische Universität München \\ D-85748 Garching \\ Germany \\ Fax: +49-89-289-12473 \\ E-mail:wdoster@ph.tum.de \\ Presented at the 3rd International \\ Conference on High Pressure \\ Bioscience and Biotechnology, \\ Rio de Janeiro, RJ, Brazil, \\ September 27-30, 2004. \\ Reesearch supported by the Deutsche \\ Forschungsgemeinschaft, Research \\ Project "High Pressure Treatment \\ of Food".}

Received January 21, 2005 Accepted May 10, 2005

\begin{abstract}
Pressure-induced dissociation of a turbid solution of casein micelles was studied in situ in static and dynamic light scattering experiments. We show that at high pressure casein micelles decompose into small fragments comparable in size to casein monomers. At intermediate pressure we observe particles measuring 15 to $20 \mathrm{~nm}$ in diameter. The stability against pressure dissociation increased with temperature, suggesting enhanced hydrophobic contacts. The pressure transition curves are biphasic, compatible with a temperature (but not pressure)dependent conformational equilibrium of two micelle species. Our thermodynamic model predicts an increase in structural entropy with temperature.
\end{abstract}

Key words

- Casein micelles

- High-pressure light

scattering

- Pressure dissociation

\section{Introduction}

Casein micelles are poly-disperse, roughly spherical aggregates in milk with a mean radius of $150 \mathrm{~nm}$. Their main physiological task is to transport calcium, proteins and phosphorus to neonates. The micelles are composed of four different phospho-proteins $\alpha_{\mathrm{S}^{-}}, \alpha_{\mathrm{S} 2^{-}}, \beta-, \kappa$-casein and calcium phosphate (1). The structure of casein micelles is still a matter of debate (2-4). Casein submicelle models propose smaller units consisting mainly of caseins, which are linked by small calcium phosphate clusters (5), while other models deny casein sub-micelles and consider calcium phosphate cluster as growing centers for caseins (6). The dual binding model of Horne $(7,8)$ is based on primary structures of caseins, which show distinct hydrophilic and hydrophobic regions along the protein chain. According to this model, caseins can be described as block copolymers. The hydrophilic regions in $\alpha_{\mathrm{S}^{-}}, \alpha_{\mathrm{S} 2^{-}}$, and $\beta$-casein are rich in phospo-serines, to which the colloidal calcium phosphate particles become attached. The casein micelle is stabilized by a hydrophobic core and hydrophilic fringes on the surface and by electrostatic coupling to calcium phosphate particles.

Both hydrophobic and electrostatic interactions decrease with pressure, which generally leads to dissociation and unfolding of proteins. Casein micelles disintegrate irreversibly under pressure.

As demonstrated by ex-situ measurements using static and dynamic light scattering $(3,9)$ and imaging techniques such as electron mi- 
croscopy $(10,11)$ or atomic force microscopy (12), high pressure reduces the hydrophobic interactions between the caseins inside the micelle. Increased exposure of hydrophobic groups was observed after pressure treatment of milk proteins (13). Moreover, pressure affects the mineral equilibrium of calcium, phosphorus and other components. Conflicting data from ex-situ measurements related to the calcium equilibrium have been presented: no effect of pressure on the free calcium concentration was found by Shibauchi et al. (14) while Anema et al. (9) found an increased calcium concentration after a pressure treatment of $200 \mathrm{MPa}$.

\section{Material and Methods}

Casein micelles were extracted from commercial-grade skim milk by combined uniform transmembrane pressure micro-filtration (mean pore diameter: $0.1 \mu \mathrm{m}$ ) and ultrafiltration, concentrated by five washing steps and dried in a spraying tower. The fractionation procedure has been described in detail by Tolkach and Kulozik (15). Casein powder was dissolved in filtered $0.1 \mathrm{M} \mathrm{Mes/}$ Tris- $\mathrm{HCl}$ solution at a concentration of 40 $\mathrm{mg} / \mathrm{ml}$ and the $\mathrm{pH}$ was adjusted to 7.3 with $\mathrm{HCl}$. All solutions were equilibrated by thoroughly stirring for $5 \mathrm{~h}$ at $20^{\circ} \mathrm{C}$.

Turbid casein solutions (3\%) were studied by photon correlation spectroscopy in a back-scattering geometry to reduce multiple scattering of light. An He-Ne-laser light source $(\lambda=632.4 \mathrm{~nm})$ from an ALV-NIBS System (ALV-Laser GmbH, Langen) was focused on an optical SITEC high-pressure cell. In dilute solutions the single-scattered intensity of light is proportional to the square of the molecular weight, the concentration and the molecular form factor. The scattered intensity is thus heavily biased by highmolecular weight particles.

We employed dynamic light scattering to analyze the molecular size distribution. These experiments showed that the pres- sure-induced dissociation process essentially involves a high-molecular weight species, the intact micelle and low-molecular weight fragments. For the present purpose, we thus used the average light intensity as an empirical indicator of the degree of dissociation of the intact micelle since the fragments do not contribute significantly to the scattering signal. After subtraction of a background intensity I $(\mathrm{P}=400 \mathrm{MPa})$ at high pressure we defined a dissociated fraction by normalizing the measured intensity $\mathrm{I}(\mathrm{P})$ by $\mathrm{I}(\mathrm{P}=1$ bar):

$\alpha=\{\mathrm{I}(\mathrm{P})-\mathrm{I}(\mathrm{P}=400 \mathrm{MPa})\} /\{\mathrm{I}(\mathrm{P}=1$ bar $)-$ $\mathrm{I}(\mathrm{P}=400 \mathrm{MPa})\} \quad$ (Eq. 1)

The size distribution was derived by expanding the measured scattered field autocorrelation function, $\mathrm{g}_{1}(\mathrm{t})$ in terms of exponentials:

$g_{1}(\mathrm{t})=\int_{0}^{\infty} G(\Gamma) \exp (-\Gamma \mathrm{t}) d \Gamma$

where $G(\Gamma)$ is the distribution of relaxation rates, $\Gamma(q)=q^{2} D(R)$, where $q$ denotes the scattering vector. $D(R)$ is the diffusion coefficient depending on the effective hydrodynamic radius according to the Stokes-Einstein relation: $\mathrm{D}=\mathrm{KT} /(6 \pi \eta \mathrm{R}), \eta$ is the viscosity of the solvent.

$\mathrm{G}(\Gamma)$ was derived using the Laplace-inversion program CONTIN. For a particular value of $R$ the distribution is given by $P_{z}(R)$ $=\mathrm{n}(\mathrm{R}) \cdot \mathrm{M}(\mathrm{R})^{2}$, where $\mathrm{n}$ is the number density of particles with radius $\mathrm{R}$ and $\mathrm{M}$ is their molecular mass. Assuming spherical, compact particles, $M \propto R^{3}$, one can derive an estimate of the number distribution $n(R)$.

\section{Results}

Dynamic and static light scattering experiments were performed at $177^{\circ}$ with turbid casein solutions at various pressures. Figure 1 displays the distribution $\mathrm{P}_{\mathrm{z}}(\mathrm{R})$ at $0.1 \mathrm{MPa}$, which is dominated by micelles with diameters near $300 \mathrm{~nm}$. The micelles 
were rather poly-disperse, with the half width of the distribution corresponding to $100 \mathrm{~nm}$. At $100 \mathrm{MPa}$ the turbidity had nearly vanished, but the $\mathrm{z}$-average of $\mathrm{R}$ was still dominated by $300-\mathrm{nm}$ particles. At low turbidity it became possible to determine the number average, which is shown in Figure 1. Now the dominant particle size was $15-20 \mathrm{~nm}$. At 300 MPa most fragments were reduced to the monomer level with diameters close to $3 \mathrm{~nm}$.

Figure 2 displays pressure-temperature dissociation plots derived from the average light scattering intensity in $177^{\circ}$ back-scattering geometry. The dissociation of casein into small fragments, $\mathrm{M} \rightarrow \mathrm{F}$, was complete at $350 \mathrm{MPa}$ at all temperatures. The location of the midpoint of the transition on the pressure scale increased with increasing temperature. The forces that stabilize the micelle, thus increased with temperature. Moreover, the transition curves were not as smooth as expected for a simple two-state mechanism. In the temperature range between 30 and $60^{\circ} \mathrm{C}$, a plateau emerged, suggesting the existence of an intermediate state.

Since the fragments differed in size and molecular weight from the intact micelle at least by a factor of ten, they contributed only weakly to the average light scattering intensity. The measured dissociated fraction $\alpha$ (Equation 1) is thus dominated by the highmolecular weight micelle fraction. This means that the plateau in $\alpha$ at the $50 \%$ level in Figure 2 cannot be attributed to a partially dissociated intermediate state with two fragments of approximately equal size. Since we do not observe fragments of the appropriate size $(100 \mathrm{~nm})$, a purely sequential dissociation process is not compatible with the data. Instead we suggest a parallel model, which assumes two types of casein micelles, which differ in stability.

At low temperatures the dominant form was the pressure-unstable state $\mathrm{M}_{\mathrm{L}}$, while with increasing temperature a high-temperature form, $\mathrm{M}_{\mathrm{H}}$, was increasingly present and was more stable.
Thermodynamic analysis of pressuretemperature dissociation of casein micelles

Pressure-induced dissociation of casein micelles is not fully reversible due to dissociation between colloidal calcium and phos-

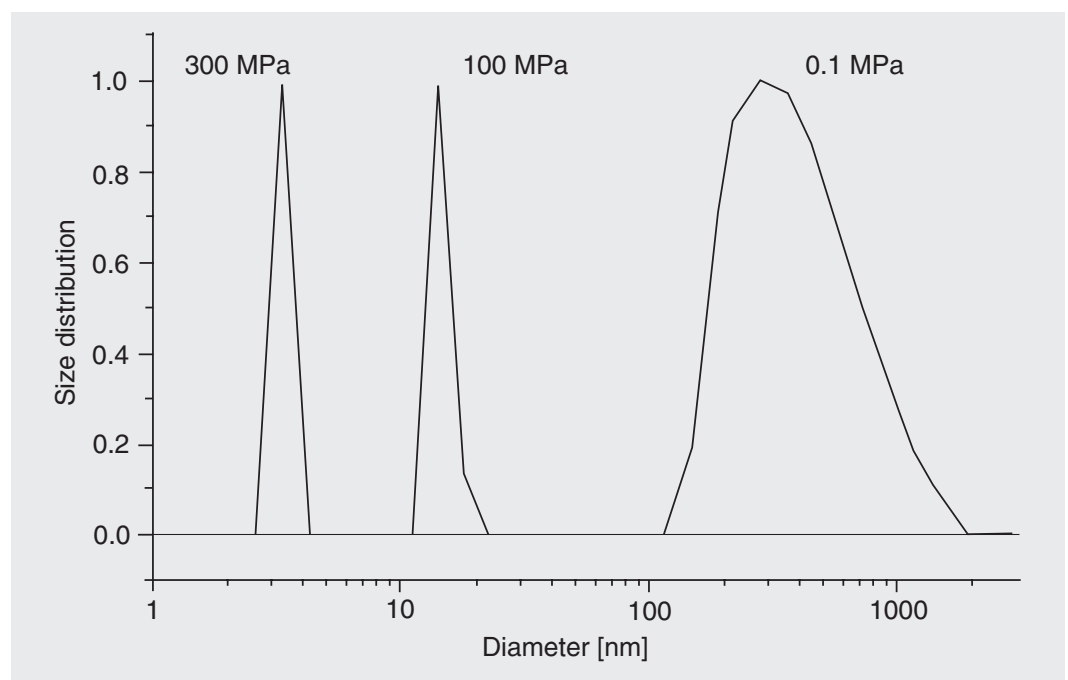

Figure 1. In situ size distribution of casein particles at three pressures derived from the intensity correlation function, $z$-distribution at $0.1 \mathrm{MPa}$ and number distribution at 100 and $300 \mathrm{MPa}$ (see text).

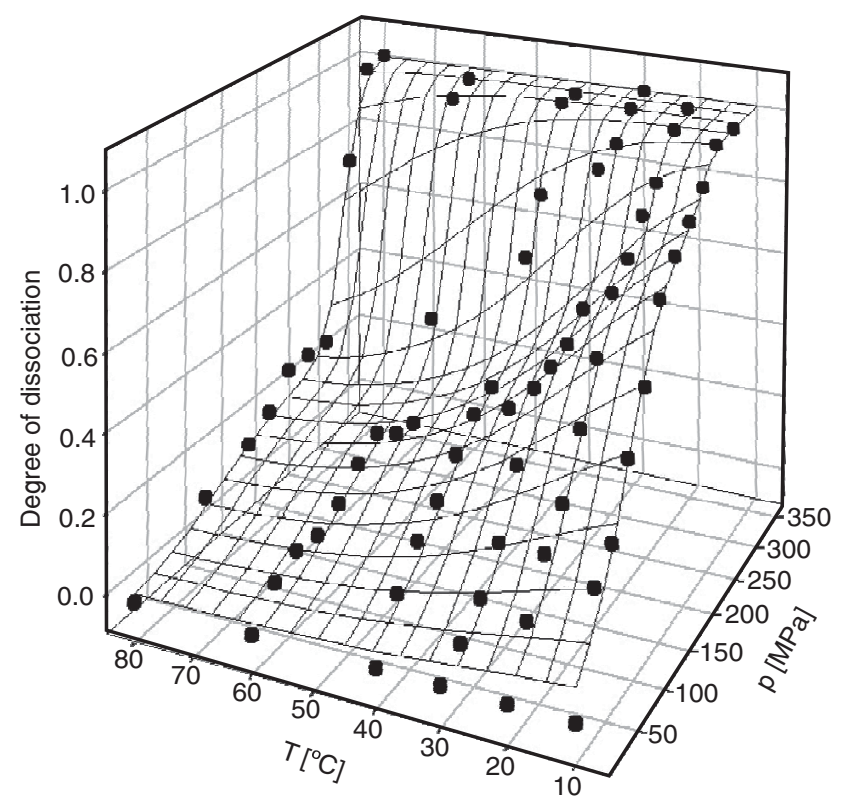

Figure 2. Temperature-pressure profile of the dissociated fraction of casein micelles $(\mathrm{pH}$ 7.3) and simultaneous fit according to the model of Equations 4-8. 
phate particles (11). This process, which is associated with the formation of 15- to 20$\mathrm{nm}$ particles (Figure 1), is slow. Thus, on a time scale of $30 \mathrm{~min}$ one can determine stable, time-independent values of scattered light. With this restriction, we performed a thermodynamic analysis of the transition curves. Next we consider an equilibrium of two types of micelles, $\mathrm{M}_{\mathrm{L}}$ and $\mathrm{M}_{\mathrm{H}}$, which dissociated under pressure into fragments $\mathrm{F}_{\mathrm{L}}$ and $\mathrm{F}_{\mathrm{H}}$ :

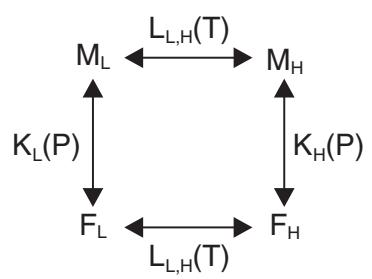

The difference in chemical potential between $\mathrm{M}_{\mathrm{L}}$ and $\mathrm{M}_{\mathrm{H}}$ follows from the GibbsDuhem relation:

$$
\begin{aligned}
& \Delta \mu_{H L}=\Delta \mu_{0}-\Delta S_{H L}^{0}\left(T-T_{0}\right)-\Delta C_{P}\left\{T\left(\operatorname{In} \frac{T}{T_{0}}\right)+T_{0}\right\}+ \\
& \Delta V_{H L}\left(P-P_{0}\right)+R T \cdot \operatorname{InL} L_{H L}
\end{aligned}
$$

$\Delta \mu_{0}$ is the potential of the reference state, $\Delta \mathrm{S}_{\mathrm{HL}}$ denotes the difference in molar entropy and $\Delta \mathrm{V}_{\mathrm{HL}}$ denotes the respective volume difference. $\Delta C_{P}$ is the difference heat capacity at constant pressure between the $\mathrm{H}$ and $\mathrm{L}$ forms. The difference in chemical potential vanishes in equilibrium, $\Delta \mu_{\mathrm{HL}}=0$. Thus, at the reference temperature and pressure one has:

$\Delta \mu_{0}=-\mathrm{RT} \ln \mathrm{L}_{\mathrm{HL}}$

The equilibrium constant, $\mathrm{L}_{\mathrm{HL}}$, is defined by the ratio of the molar concentrations if the solution is diluted: $\mathrm{L}_{\mathrm{HL}}=\mathrm{N}_{\mathrm{H}} / \mathrm{N}_{\mathrm{L}}$. If the reference temperature and pressure, $\mathrm{T}_{0}$ and $\mathrm{P}_{0}$, are chosen at the midpoint of the HL equilibrium, $\mathrm{N}_{\mathrm{H}}=\mathrm{N}_{\mathrm{L}}$, and the reference potential vanishes: $\Delta \mu_{0}=0$.

The equilibrium is controlled by the entropy difference $\Delta \mathrm{S}_{\mathrm{HL}}(\mathrm{T})$, which decreases with increasing temperature. This implies a finite difference in the heat capacities, $\Delta \mathrm{C}_{\mathrm{HL}}$ $\neq 0$.

We can fit the data ignoring the pressure dependence of the conformational equilibrium; thus $\Delta \mathrm{V}_{\mathrm{HK}} \approx 0$.

The fraction of the dissociated conformer $\alpha_{\mathrm{H} / \mathrm{L}} \mathrm{H}$ or $\mathrm{L}$ is controlled by the pressuredependent constants $\mathrm{K}_{\mathrm{L}}$ and $\mathrm{K}_{\mathrm{H}}(\mathrm{P})$ :

$\alpha_{L / H}(P)=\frac{K_{L / H}(P)}{1+K_{L / H}(P)}$

and

$\ln K_{L H, F}(\mathrm{P})=\ln K_{L / H, F}(\mathrm{P}=0)-1 /(\mathrm{RT}) \times \mathrm{P} \times$ $\Delta \mathrm{V}_{\mathrm{H} / \mathrm{L}, \mathrm{F}}+\Delta \mathrm{S}_{\mathrm{H} / \mathrm{L}, \mathrm{F}} / \mathrm{R}$

$\Delta \mathrm{V}_{\mathrm{H} / \mathrm{L}, \mathrm{F}}$ and $\Delta \mathrm{S}_{\mathrm{H} / \mathrm{L}, \mathrm{F}}$ are the volume and entropy differences between the $\mathrm{H}$ or $\mathrm{L}$ form and its fragments $F$. The combined dissociation fraction is then given by:

$\alpha_{t o t}(P, T)=\frac{1}{\left(1+L_{H L}\right)} \cdot \alpha_{L}+\frac{L_{H L}}{\left(1+L_{H L}\right)} \cdot \alpha_{H}$ (Eq. 8)

In its present form the model is overdetermined with 8 parameters. The simplest model fitting the data was based on the assumption that the $\mathrm{H} \leftrightarrow \mathrm{L}$ equilibrium is only temperature dependent, $\Delta \mathrm{V}_{\mathrm{HL}} \approx 0$ and that the dissociation of $\mathrm{H}$ or $\mathrm{L}$ into fragments is only pressure but not temperature dependent. This implies $\Delta \mathrm{S}_{\mathrm{H} / \mathrm{L}, \mathrm{F}} \approx 0$. Global fits to all transition curves were performed, and are represented by the full lines in Figure 2. The correlation coefficient of the fit was 0.98 and the residuals did not exhibit any systematic deviations. The resulting parameters are listed in Table 1. The dissociation constant $\mathrm{K}_{\mathrm{L}}(0)$ $=0.09$ of the low temperature form is small, favoring intact micelles at ambient pressure. The dissociation volume, $\Delta \mathrm{V}_{\mathrm{LF}}=-61 \pm 7 \mathrm{ml} /$ $\mathrm{mol}$, is negative and surprisingly small. The dissociation constant of the high temperature form $\mathrm{H}, \mathrm{K}_{\mathrm{H}}(0)=9.5 \times 10^{-10}$, is negligible at ambient pressure, while the dissociation volume, $\Delta \mathrm{V}_{\mathrm{HF}}=-204 \pm 3 \mathrm{ml} / \mathrm{mol}$, is again negative and significantly larger in comparison with the $\mathrm{L}$ form. The positive $\Delta \mathrm{S}_{\mathrm{HL}}=$ $150 \pm 10 \mathrm{~J} /(\mathrm{mol} \cdot \mathrm{K})$ implies that the $\mathrm{H}$ form 
is more stable than the $\mathrm{L}$ form at high temperature and vice versa. Introducing a finite heat capacity change noticeably improves the quality of the fits. The resulting difference, $\Delta \mathrm{C}_{\mathrm{HL}} \approx-0.5 \mathrm{~kJ} /(\mathrm{mol} \cdot \mathrm{K})$, is smaller than heat capacity changes found in denaturation experiments with small proteins. However, the sign of $\Delta \mathrm{C}_{\mathrm{HL}}$ is negative, implying that the $\mathrm{H}$-form exhibits a lower heat capacity than the L-form in spite of its larger entropy. Figure 3 shows the resulting temperature-dependent populations of $\mathrm{H}$ and $\mathrm{L}$. The pressure-induced dissociation transition is monophasic at high temperatures since only the high-temperature form $\mathrm{H}$ is present. At low temperatures both species, $\mathrm{L}$ and $\mathrm{H}$, contribute. The midpoint temperature is $\mathrm{T}_{0}=$ $307 \pm 2 \mathrm{~K}$, independent of the pressure.

In conclusion, in situ light scattering measurements demonstrate that casein micelles $(\mathrm{d} \approx 200 \mathrm{~nm})$ disintegrate at pressures above $300 \mathrm{MPa}$ into 3-nm particles, most likely casein monomers or small oligomers. We also observe particles of intermediate size near $15 \mathrm{~nm}$, which represent either intermediate states or aggregates of casein monomers, which evolve a posteriori to pressure dissociation. The pressure required to dissociate the micelles increases with temperature in accordance with hydrophobic stabilization. A continuous enhancement of hydrophobic interactions would simply shift the midpoint of the transition on the pressure scale. Instead we observe two discrete steps with a temperature-dependent partition: with increasing temperature the fraction of a low temperature form $(\mathrm{L})$ decreases in favor of a high temperature form $(\mathrm{H})$, which is more pressure stable.

The thermodynamic analysis based on Equation 3 indicates that the $\mathrm{H}$-form is more disordered, $\mathrm{T}_{0} \cdot \Delta \mathrm{S}_{\mathrm{HL}}=46 \mathrm{~kJ} / \mathrm{mol}\left(\mathrm{T}_{0}=307\right.$ $\mathrm{K})$, and exhibits a larger dissociation volume, 204 versus $61 \mathrm{ml} / \mathrm{mol}$, than the Lmicelle (Table 1). This could suggest that the high-temperature form has an open structure, while the L-form is more compact.
Table 1. Parameters of simultaneous fit to the model of Equation 3.

\begin{tabular}{lc}
\hline Parameters & Values at pH 7.3 \\
\hline $\mathrm{K}_{\mathrm{L}}(0)$ & $0.09 \pm 0.02$ \\
$\Delta \mathrm{V}_{\mathrm{LF}}$ & $-61 \pm 7 \mathrm{ml} / \mathrm{mol}$ \\
$\mathrm{K}_{\mathrm{H}}(0)$ & $9.5 \times 10^{-10}$ \\
$\Delta \mathrm{V}_{\mathrm{HF}}$ & $-204 \pm 3 \mathrm{ml} / \mathrm{mol}$ \\
$\mathrm{T}_{0}$ & $307 \pm 2 \mathrm{~K}$ \\
$\Delta \mathrm{S}_{\mathrm{HL}}\left(\mathrm{T}_{0}\right)$ & $149 \pm 10 \mathrm{~J} /(\mathrm{mol} \cdot \mathrm{K})$ \\
$\mathrm{T}_{0} \Delta \mathrm{S}_{\mathrm{HL}}$ & $46 \mathrm{~kJ} / \mathrm{mol}$ \\
$\Delta \mathrm{C}_{\mathrm{HL}}$ & $-0.5 \pm 0.15 \mathrm{~kJ} /(\mathrm{mol} \cdot \mathrm{K})$
\end{tabular}

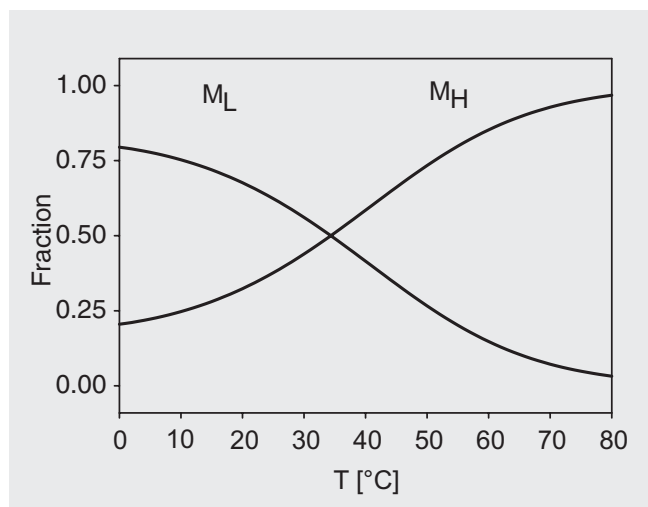

However, the $\mathrm{H} \leftrightarrow \mathrm{L}$ equilibrium is approximately pressure independent, and thus the volume difference $\Delta \mathrm{V}_{\mathrm{HL}}$ must be small. This implies that the fragments of $\mathrm{H}$ and $\mathrm{L}, \mathrm{F}_{\mathrm{L}}$ and $\mathrm{F}_{\mathrm{H}}$ differ in volume. However, due to the small size of the fragments they contribute very little to the observed scattering intensity. Thus, no information about the $\mathrm{F}_{\mathrm{L}} \leftrightarrow \mathrm{F}_{\mathrm{H}}$ equilibrium is obtained from the light scattering data. The apparent volume difference is derived from the width of the pressure transition. It is likely that the apparent difference in the dissociation volumes, $\Delta \mathrm{V}_{\mathrm{HF}}, \Delta \mathrm{V}_{\mathrm{LF}}$, reflects a difference in heterogeneity of the size and stability of the $\mathrm{L}$ and $\mathrm{H}$ micelles, which will broaden the transition. The dissociation constants of $\mathrm{H}$ and $\mathrm{L}, \mathrm{K}_{\mathrm{H}}(\mathrm{P})$ and $\mathrm{K}_{\mathrm{L}}(\mathrm{P})$, depend only on the pressure but not on the temperature. This implies that the entropic difference between micelle and fragments must be small, $\Delta \mathrm{S}_{\mathrm{H} / \mathrm{L}, \mathrm{F}} \approx 0$. Since $\mathrm{H}$ and $\mathrm{L}$ differ in entropy, one must conclude
Figure 3. Temperature-dependent population the low $(\mathrm{L})$ and high $(\mathrm{H})$ temperature conformer of casein micelles at ambient pressure according to the model of Equation 3. 
that $\Delta \mathrm{S}_{\mathrm{HL}}$ is stored in the respective fragments $\Delta \mathrm{S}_{\mathrm{HL}} \approx \Delta \mathrm{S}_{\mathrm{F}, \mathrm{H} / \mathrm{L}}$. We observe indeed two distinct fragments corresponding to particle sizes near $3 \mathrm{~nm}$ and $15 \mathrm{~nm}$. But the arguments concerning the fragments given above apply again. Moreover, the pressureinduced dissociation process is only partially reversible. The main result of this in situ pressure work is the finding of two states of native-like casein micelles, which differ in sensitivity to pressure dissociation. The $\mathrm{H}$ form is dominant at high temperatures. We are presently investigating whether the two states differ in the manner how calcium phosphate particles are bound. The model should be considered as rather preliminary, and further extensions for explicit inclusion of heterogeneity and size distribution are in progress.

\section{References}

1. Walstra P \& Jenness R (1984). On the stability of casein micelles. Journal of Dairy Science, 73: 1965-1979.

2. Dalgleish DG, Spagnuolo PA \& Goff HD (2004). A possible structure of the casein micelle based on high-resolution field-emission scanning electron microscopy. International Dairy Journal, 14: 10131089.

3. Desobry-Banon S, Richard F \& Hardy J (1994). Study of acid and rennet coagulation of high pressurized milk. Journal of Dairy Science, 77 : 3267-3274.

4. McMahon DJ \& McManus WR (1998). Rethinking casein micelle structure using electron microscopy. Journal of Dairy Science, 81: 2985-2993.

5. Walstra P (1999). Casein sub-micelles: do they exist? International Dairy Journal, 9: 189-192.

6. Holt C, de Kruif CG, Tuinier R et al. (2003). Substructure of bovine casein micelles by small-angle $\mathrm{X}$-ray and neutron scattering. Colloids and Surfaces A, 213: 275-284.

7. Horne DS (1998). Casein interactions: casting light on the black boxes, the structure in dairy products. International Dairy Journal, 8 : 171-177.

8. Horne DS (2003). Casein micelles as hard spheres: limitations of the model in acidified gel formation. Colloids and Surfaces A: Physicochemical and Engineering Aspects, 213: 255-263.

9. Anema SG, Lee SK, Schrader K et al. (1997). Effect of $\mathrm{pH}$ on the turbidity of pressure-treated calcium caseinate suspensions and skim milk. Milchwissenschaft, 52: 141-146.

10. Needs EC, Stenning RA, Gill AL et al. (2000). High pressure treatment of milk: Effects on casein micelle structure and on enzyme coagulation. Journal of Dairy Research, 67: 31-42.

11. Keenan RD, Hubbard CD, Mayes DM et al. (2003). Role of Calcium Phosphate in High Pressure-Induced Gelation of Milk. Food Colloids-Biopolymers and Materials, Royal Society of Chemistry, Cambridge, UK, 109-118.

12. Regnault S, Thiebaud M, Dumay E et al. (2004). Pressurisation of raw skim milk and of a dispersion of phosphocaseinate at $9^{\circ} \mathrm{C}$ or $20^{\circ} \mathrm{C}$ : effects on casein micelle size distribution. International Dairy Journal, 14: 55-68.

13. Gaucheron F, Famelart M, Mariette F et al. (1997). Combined effects of temperature and high pressure on physicochemical characteristics of skim milk. Food Chemistry, 59: 439-447.

14. Shibauchi $Y$, Yamamoto H, Sagara $Y$ et al. (1992). Pressure-induced conformational changes of casein micelles. In: Heremans $\mathrm{K} \&$ Masson $\mathrm{P}$ (Editors), High Pressure and Biotechnology. Colloque INSERM. Vol. 224. John Libbey Eurotext Ltd., London, UK.

15. Tolkach A \& Kulozik $U$ (2005). Fractionation of whey proteins and caseino-macropeptide by means of enzymatic cross-linking and membrane separation techniques. Journal of Food Engineering, 67: 13-20. 